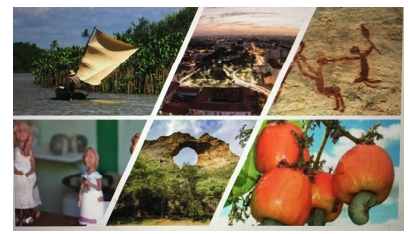

ISBN: 2675-1496 DOI: https://doi.org/10.26694/caedu.v1i2.9181

\title{
FORMACIÓN E IDENTIDAD DOCENTE: IMAGINARIOS DE LAS EDUCADORAS EN EL MÉXICO DEL SIGLO XX
}

\author{
Mercedes Guadalupe Muñiz Vega \\ Instituto del Potosí \\ ORCID: http://orcid.org/0000-0002-5275-1362 \\ María del Rosario Auces Flores \\ Universidad Autónoma de San Luis Potosí \\ ORCID: http://orcid.org/0000-0002-3785-4822
}

Blanca Susana Vega Martínez

Doctora en Humanidades

Universidad Autónoma de San Luis Potosí

ORCID: http://orcid.org/0000-0002-5298-9442

\section{Resumen}

Este artículo aborda los procesos de formación e identidad docente a partir de las trayectorias profesionales de dos educadoras, desde sus condiciones de género hasta su formación como profesionistas en el contexto del México contemporáneo. La investigación se elaboró mediante el método biográfico, a través de entrevistas a profundidad y escritos autobiográficos. El análisis de la información proporcionada se realizó a partir de tres dimensiones siguiendo a Cacho (2004): el tiempo biográfico, el tiempo educativo y el tiempo histórico, en los cuales se muestra la percepción que las educadoras tienen sobre sí mismas como resultado de sus experiencias personales, formativas y laborales, de acuerdo al contexto socio cultural en el que cada una de ellas se desarrolló.

La finalidad de este estudio fue coadyuvar a comprender una realidad social distinta de las educadoras en comparación con la de otras profesiones. En particular se considera que formarse y pensarse como educadoras se relaciona de manera directa con un imaginario social que históricamente posicionó a las mujeres desde estereotipos que las colocan en un lugar de subalternidad. Por ello, concluimos que es indispensable seguir cuestionando las implicaciones ideológicas, políticas y sociales en el campo de la formación y la identidad docente de las mujeres.

Palabras-clave: Educación preescolar. Formación de profesoras. Identidad docente. Trayectoria profesional. 


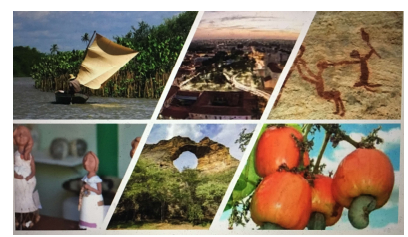

ISBN: 2675-1496 DOI: https://doi.org/10.26694/caedu.v1i2.9181

\section{FORMAÇÃO E IDENTIDADE DOCENTE: IMAGINÁRIOS DAS EDUCADORAS NO MÉXICO DO SÉCULO XX}

\section{Resumo}

Este artigo aborda os processos de formação e identidade docente a partir das trajetórias profissionais de duas educadoras, desde suas condições de gênero até sua formação como profissionais no contexto do México contemporâneo. A pesquisa foi desenvolvida mediante o método biográfico, através de entrevistas com profundidade e escritos autobiográficos. A análise das informações fornecidas foi feita a partir de três dimensões, segundo Cacho (2004): o tempo biográfico, o tempo educacional e o tempo histórico, nos quais é demonstrada a percepção que as professoras têm sobre si mesmas como resultado de suas experiências pessoais, laborais e de formação, de acordo com o contexto sociocultural em que cada uma delas se desenvolveu.

O objetivo deste estudo foi ajudar a compreender uma realidade social diferente das educadoras em comparação com a de outras profissões. Em particular, considera-se que se formar e pensar como educadoras está diretamente relacionado a um imaginário social que historicamente posicionou as mulheres a partir de estereótipos que as colocam em um lugar de subalternidade. Portanto, concluímos que é essencial continuar questionando as implicações ideológicas, políticas e sociais no campo da formação e da identidade docente das mulheres.

Palavras-chave: Educação pré-escolar. Formação de professoras. Identidade docente Trajetória profissional.

TRAINING AND TEACHER'S IDENTITY:

IMAGINARIES OF FEMALE EDUCATORS IN 20th CENTURY MEXICO

\section{Abstract}

This article deals with the processes of teacher training and identity based on the professional trajectories of two educators, from their gender conditions to their training as professionals in the context of contemporary Mexico. The research was developed using the biographical method, through in-depth interviews and autobiographical writings. The analysis of the information provided was made from three dimensions, according to Cacho (2004): the biographical time, the educational time and the historical time, in which it shows the perception that female teachers have about themselves as a result of their personal, training and work experiences, according to the sociocultural context in which each one of them was raised.

The purpose of this study was to help the comprehension of a different social reality of teachers, in comparison to other professions. In particular, it is considered that training and thinking as educators is directly related to a social imaginary that historically positioned women, inspired by stereotypes that put them in a place of subalternity. Therefore, we conclude that it is essential to continue questioning the ideological, political and social implications in both the field of training and the female teacher identity

Keywords: Preschool education. Teacher training. Teacher identity. Career path. 


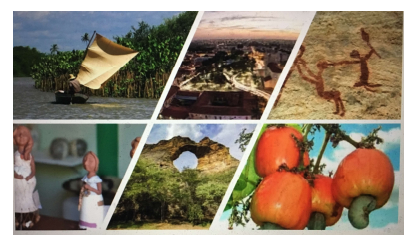

ISBN: 2675-1496 DOI: https://doi.org/10.26694/caedu.v1i2.9181

\section{Introducción}

El rescate de las historias de las mujeres que se dedicaron a la educación es una contribución a los estudios de género y de las mujeres, ya que conlleva al entendimiento de la feminización del magisterio y al estatus de subordinación en el que se mantuvieron históricamente. Es por ello que este artículo pretende contribuir a dichos estudios presentando parte de una investigación cuyo objetivo fue reconocer la presencia de las mujeres en los espacios del magisterio y advertir cómo fue su preparación y bajo qué condiciones, ya que muchas de ellas atravesaron por procesos complejos en su formación como profesoras, por ejemplo, currículos sexuados, estereotipos definidos o prácticas docentes determinadas por su género.

Los estudios historiográficos sobre las maestras y con los que actualmente contamos nos ayudan a entender cuáles eran los imaginarios sociales que sostenían a la docencia en educación básica como semiprofesión y cómo sigue siendo necesario hoy en día transformar estas concepciones para la dignificación del trabajo de las educadoras en aras de lograr una mayor equidad y justicia social. De ahí la importancia de cuestionar y analizar las implicaciones ideológicas, políticas y sociales que tiene en la actualidad este fenómeno en el campo de la formación y la identidad docente.

En este artículo presentamos dos relatos de educadoras los cuales analizamos a partir de tres dimensiones y apelando el enfoque biográfico. Un hallazgo importante fue reconocer cómo se reproducen o, por el contrario, se encuentran actos de resistencia sobre lo que significa "ser mujer" y "ser educadora", que se construyen desde las instituciones y a través de las relaciones sociales que se establecen con la comunidad como parte vital de su quehacer profesional.

\section{La importancia de los estudios de/con profesoras}




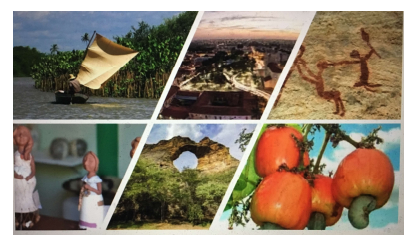

ISBN: 2675-1496 DOI: https://doi.org/10.26694/caedu.v1i2.9181

La formación e identidad de profesoras en México ha sido un tema recurrente en los estudios sobre educación. En éstos, se busca dar cuenta de los contextos que enfrentaron las mujeres que optaron por el magisterio desde el siglo XIX hasta principios del siglo XX.

Históricamente, en México la educación de los niños representaba un bajo costo al quedar a cargo del trabajo femenino ya que se consideraba innecesaria la preparación de las mujeres como profesoras. Esta situación podía observarse incluso en otros países. Scott (2001) comenta que en Estados Unidos el costo de los gastos en educación era menor si estaba a cargo de las mujeres, ya que se consideraban, según el imaginario social, que éstas eran "menos productivas que los hombres, menos codiciosas, además de que prestarían servicios por salarios de subsistencia”.

Escalante (2013), recupera las concepciones que se tenían de las profesoras en el siglo XIX desde su condición de mujer como "natural, analfabeta y barata"; explica que se le consideraba "natural" por las características sexuales que se relacionaban con la maternidad y el cuidado de los niños; "analfabeta" por el imaginario que se tenía acerca de que las mujeres no contaban con la misma capacidad cognitiva que los hombres para enseñar; por último, se le consideraba "barata" porque al no contar con la misma actividad intelectual que los hombres representaría bajos costos tanto en su formación como en el trabajo que desarrollarían, por lo que la inversión era menor.

Por su parte, García (2008) afirma que, a pesar de la preocupación por fundar escuelas normales para profesoras con el propósito de terminar con el imaginario de las maestras "improvisadas" del siglo XVIII, se instauró un nuevo imaginario: el de la maestra "soltera", el cual determinaba que una maestra casada debía abandonar el magisterio. Esta situación, causó que se antepusiera el apelativo de "señorita" a las profesoras, el cual perduró más allá del siglo XX.

En palabras de López y Galván (2008):

El imaginario hegemónico privaba a las mujeres de una posición socioprofesional plena y las situaba de manera permanente como 


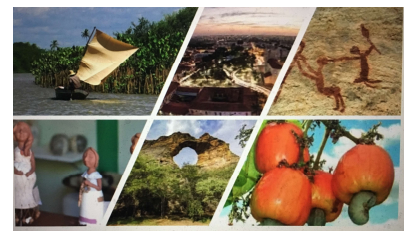

ISBN: 2675-1496 DOI: https://doi.org/10.26694/caedu.v1i2.9181

subordinadas, como empleadas semiprofesionales al servicio de instituciones educativas segregadas o dirigidas por hombres ( $\mathrm{p}$. 23).

Posterior a los años de la revolución surgió una nueva identidad femenina, la cual tenía mayor reconocimiento social pues antes, durante y después de la guerra participó en los proyectos políticos y educativos. Sin embargo, la participación de las mujeres en dichos proyectos fue pasiva ya que, a pesar de participar, seguían bajo las órdenes y dirección de los hombres.

Con relación al papel de subordinación de las mujeres en la educación, López (2008) identifica que esta situación atendía a intereses del Estado. Por lo general a las mujeres se les otorgaban tareas distintas y de menor valor que a sus compañeros varones, por ejemplo, la política sexual las orientaba al celibato o al matrimonio tardío. La educación de los niños era una actividad considerada propia de su sexo, además, estaban designadas a enseñar actividades domésticas y, en consecuencia, percibían salarios más bajos que los hombres.

Reflexionar sobre su lucha por permanecer en el magisterio nos ayuda a entender que las maestras son sujetos con agencia que realizan acciones concretas en las aulas. Street (2006) señala que conocer las vidas de algunas mujeres con nombre y apellido contribuye a enriquecer nuestro entendimiento de las identidades profesionales actuales.

Es por ello, que los estudios de profesoras abren las puertas a un campo interdisciplinario en el que convoca a educadores y otros profesionales a interesarse sobre sus implicaciones en el presente y en el futuro. Estudiar la construcción histórica de la formación de las maestras nos ofrece la oportunidad de transformar el orden establecido que durante años prescribe la identidad de las maestras con la posibilidad de pensar en un mundo diferente.

Este escrito apoya a la generación de conocimiento y coadyuva a comprender una realidad social distinta de las educadoras en comparación a la de otras profesiones en las que el género no desempeña un papel en específico. Ya que, tal y como lo afirma López 


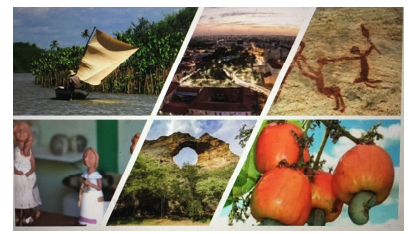

ISBN: 2675-1496 DOI: https://doi.org/10.26694/caedu.v1i2.9181

(2006), el rescate de las historias de las maestras conlleva el derecho colectivo a una nueva identidad femenina y profesional.

\section{El enfoque biográfico, construcción del relato y análisis de narrativas}

La metodología que se llevó a cabo en esta investigación fue de corte cualitativo, la cual permitió profundizar en las construcciones y vivencias de cada educadora, al mismo tiempo que reflejó las singularidades de sus trayectorias de vida de acuerdo al contexto y sus interacciones con los otros (Bolívar, 2005). Se utilizó el método biográfico a partir de la entrevista a profundidad, y posteriormente se construyeron los relatos de vida. A decir de Goodson (2004) el objetivo fundamental de las investigaciones basadas en el enfoque biográfico consiste en localizar el propio relato del profesor, en este caso, educadoras, en el marco de un análisis contextual más amplio a través de entrevistas, discusiones y análisis de textos y contextos.

Se realizaron cuatro entrevistas (con una duración de una hora cada una) a dos educadoras que practicaban su ejercicio profesional en la ciudad de San Luis Potosí, México: María Eugenia y Graciela. Una vez que se compartió el propósito del estudio, tuvieron una participación libre y voluntaria, contando con el consentimiento informado y la devolución de su trayectoria profesional. Las educadoras mostraron mucha disponibilidad para contar sus experiencias de vida, incluso permitieron que algunas de sus fotografías estuvieran dispuestas para la investigación.

El análisis de las entrevistas biográficas se realizó de manera horizontal, el cual consiste en tomar las voces de ambas educadoras en función de las categorías que constituyen la identidad. También se utilizó un estilo descriptivo a partir de las dimensiones propuestas por Cacho (2004) incluyendo las voces textuales de las educadoras para fundamentar el trabajo.

Según Bolívar (2005), las entrevistas biográficas consisten en reflexionar y rememorar episodios de la vida, en el que la persona cuenta cosas de su biografía profesional. Siguiendo a Pujadas (1992) se realizaron tres versiones de los textos: uno textual, tal y como lo hablaron las educadoras, uno depurado, en el cual solamente se 


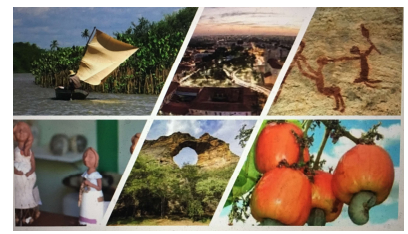

ISBN: 2675-1496 DOI: https://doi.org/10.26694/caedu.v1i2.9181

omitieron palabras repetidas sin dar un tono diferente a la conversación, y finalmente un texto en el que se sistematizó la información de manera cronológica.

Bruner (2003) plantea que tenemos identidad porque podemos contar historias sobre nosotros mismos. De manera que, utilizar el enfoque biográfico en esta investigación nos ayudó a encontrar la relación entre el pasado, el presente y las expectativas futuras de las educadoras con relación a su identidad.

\section{Identidad y formación docente como proceso indisociable}

Al hablar de identidad estamos hablando de un concepto que, por su propia naturaleza, ha sido estudiado desde diferentes enfoques. Para ello, nos referimos a la identidad como un concepto socio-antropológico perteneciente a los estudios sociales, culturales e históricos de los sujetos.

Desde esta perspectiva, Dubar (2002) afirma que cuando hablamos de identidad estamos hablando de procesos individuales y colectivos que pueden confluir de manera conjunta, es decir, la identidad se construye a partir de la concepción que el individuo tiene de la sociedad y de la percepción que tiene sobre su propio posicionamiento dentro de la misma. Es así que, el encuentro con los otros es fundamental para la configuración de la identidad de los sujetos. Al respecto, Guerrero (2002) supone que la identidad es un proceso de identificación y diferenciación el cual le permite al individuo reflexionar y confirmar su propia existencia. Él advierte, "las identidades sociales se definen a partir de una agrupación de individuos que se autodenominan y definen frente a los otros grupos como diferentes" (p. 102).

Dicho lo anterior, se puede advertir que la identidad de los individuos se configura a partir de las construcciones simbólicas que el individuo hace sobre sí mismo como resultado de sus procesos de socialización. Así pues, la identidad es una construcción social capaz de transformarse y retransformarse según el contexto histórico en el que los individuos se desenvuelven.

En este sentido, la formación se refiere al proceso en el que un individuo se apropia de los conocimientos, saberes y principios del grupo en el que se desenvuelve. A 


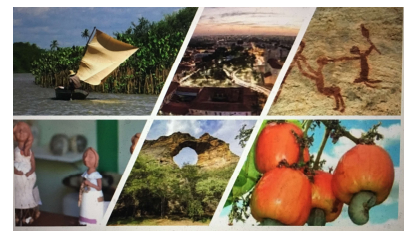

ISBN: 2675-1496 DOI: https://doi.org/10.26694/caedu.v1i2.9181

propósito, Ducoing (2005) señala que la formación es un proceso de enculturación que configura al sujeto en un determinado ámbito. De acuerdo con esto, la formación determina la conducta del individuo dentro su marco cultural. No obstante, la formación, al igual que la identidad, constituye algo más que la adquisición de conocimiento pues conlleva a la reflexión del individuo sobre sí mismo, de manera que propicia su transformación (Filloux, 2004).

De ahí que la formación suponga un proceso identitario, lo que implica a decir de Ducoing (2005), un trabajo de uno mismo para convertirse en "un sujeto que sintetiza los rasgos y características de lo que imagina" (p. 109). Es por ello que cuando hablamos de identidad y formación estamos hablando de dos procesos que conjuntamente modelan la vida de los sujetos.

Ahora bien, en el caso de los docentes, la subjetividad de los trayectos formativos juega un papel fundamental en la construcción de su identidad, Cacho (2004) advierte que el análisis de las trayectorias formativas permite reconstruir una parte del proceso de la configuración de la identidad profesional de los profesores, así como del imaginario sobre lo que implica ser docente. Éstas se estructuran a partir de tres dimensiones: La dimensión del tiempo biográfico, a través de la cual se establecen secuencias según los ciclos de vida; en la del tiempo educativo, según los ciclos y dinámicas escolares; y en la del tiempo histórico, se presentan diferentes oportunidades y limitaciones a partir del contexto social, de las políticas laborales y educativas. (p. 81)

Igualmente, Bolívar (2005, p. 4) menciona que "la identidad profesional es tanto la experiencia personal como el papel que le es reconocido en una sociedad". Por ello, el contexto histórico y la representación social de los docentes desempeñan otro elemento fundamental en la construcción de su identidad. Con relación a esto, Nias (1989) plantea que hablar de identidad es hablar de la autoimagen y todo lo que los profesores proyectan a partir de lo que los demás interpretan acerca de sí mismos. De manera que, los profesores construyen una parte de su identidad a través de la interiorización de los roles que la sociedad les otorga. 


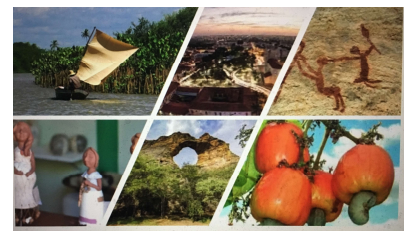

ISBN: 2675-1496 DOI: https://doi.org/10.26694/caedu.v1i2.9181

Específicamente, en el caso de las educadoras, las representaciones sociales que circulan sobre ellas alimentan las creencias, prácticas y estereotipos que subjetivaban sobre su profesión. Por ello, consideramos fundamental pensar la profesión docente de las educadoras a través de la condición de género.

\section{Dimensiones para pensar los relatos docentes.}

El análisis de los relatos de las educadoras fue trabajado mediante las dimensiones ya dichas, a partir de relatos y voces textuales de las educadoras.

La dimensión biográfica planteamos el origen familiar, su autoconcepto y su elección de carrera profesional. La dimensión del tiempo educativo se describe a través de sus experiencias escolares, los modelos docentes, su formación docente inicial, el ejercicio profesional y su contacto con el magisterio. En la dimensión social-histórica se destaca la construcción cultural de la educadora a partir de los roles y estereotipos encontrados, por ejemplo, la función social que tiene el jardín de niños, los imaginarios de la educadora ideal y la doble jornada de acuerdo a una perspectiva de género. En los relatos de ambas educadoras es observable que su condición de género estuvo presente a lo largo de todos los ámbitos de sus vidas, la cual representó un elemento fundamental para la construcción de su identidad como docentes ya que determinó la manera de concebirse y dirigirse en el desempeño de su profesión.

\section{Dimensión biográfica}

\section{Origen familiar}

María Eugenia nació en la capital de San Luis Potosí en 1966 y dedicó gran parte de su vida profesional a la educación rural y posteriormente en la capital; Graciela fue originaria de una comunidad del Estado de San Luis Potosí, nació en 1973 y toda su práctica profesional fue dedicada a la educación rural.

Ambas educadoras descendían de una familia con limitantes económicas pues Graciela advirtió la pobreza y las necesidades educativas del campo, por lo que su vida estuvo marcada por las precariedades económicas de su familia las cuales originaron que sus 


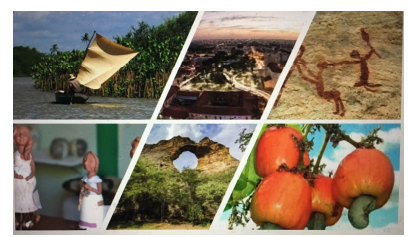

ISBN: 2675-1496 DOI: https://doi.org/10.26694/caedu.v1i2.9181

hermanos mayores abandonaran sus estudios para apoyar a la economía del hogar. Por su parte, la familia de María Eugenia se sostenía únicamente mediante la baja pensión que percibía su padre.

La situación familiar y el contexto social en el que ambas se vivieron originó que sus padres les dieran una educación que permeaba ciertos estereotipos de género atribuidos a su condición como mujer:

En casa había cuestiones muy marcadas [...] desde cómo pedir permiso hasta qué deben hacer las mujeres, cómo se deben comportar y cómo se deben comportar los hombres, qué se le tenía permitido a las mujeres y qué se le tenía permitido a los hombres [...] El hombre jugaba un rol muy diferente a lo que hoy en día es o debería de ser, por ejemplo, en esa época mi papá era el que tomaba decisiones, [...] porque era implícito su poder como proveedor económico de la familia (María Eugenia).

[...] mi mamá nos apoyaba más a las mujeres, nos decía: es que ustedes no sean como yo que no aprendí, que no estudié la primaria, ustedes échenle ganas porque esa es la herencia que yo les voy a dejar; los hombres se defienden más, los hombres pueden buscar trabajo donde ellos quieran, hay más trabajo ahorita para los hombres, ellos pueden estar trabajando en alguna fábrica. Y las mujeres decíamos: pues ¿Qué vamos a hacer nosotras? ¿Estar gritando en el centro 'pásele, 'pásele a la ropa'?, [ese] no era un trabajo seguro (Graciela).

\section{Autoconcepto}

Graciela se percibe como una persona de carácter fuerte y de personalidad reservada, lo cual ha repercutido en su relación con compañeras de trabajo, familiares y amigos. Por su parte, María Eugenia se considera como una mujer tímida, organizada, responsable y 


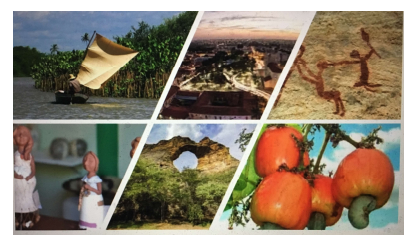

ISBN: 2675-1496 DOI: https://doi.org/10.26694/caedu.v1i2.9181

respetuosa, así mismo, reconoce que durante su infancia se percibía como una niña sumisa y obediente.

\section{Elección de carrera profesional}

En la época y el contexto social en el que María Eugenia vivió, era común que las mujeres eligieran profesiones de acuerdo a su identidad de género, por tal motivo, la mayoría optaba por convertirse en secretarias, enfermeras o maestras. A diferencia de ella, Graciela vivió en una época en la que tenía mayor libertad social para elegir una carrera y/o profesión. No obstante, ambas al ser provenientes de familias con escasos recursos económicos se vieron impuestas a cursar la profesión de maestras pues -a decir de sus familias- les proporcionaría la posibilidad de conseguir un trabajo que les permitiera solventarse económicamente por sí mismas.

De no ser por esa condición Graciela hubiera querido ser Enfermera Técnica y María Eugenia Químico Farmacobiólogo, como ellas lo señalan:

Al inicio yo quería ser enfermera $[\ldots]$ cuando fui a las preinscripciones [...] [gritan]: ¡Se acabaron las fichas! $\mathrm{Y}$ yo chillaba porque decía: ¿Y ahora qué voy a estudiar? ¿Ahora qué voy a hacer? Y [me dice] mi hermana: ¡Métete de maestra! Si tu idea es estudiar para trabajar yo te recomiendo la normal. Yo no estaba convencida, pero al final le dije [a mi hermana]: me voy a meter aquí, a ver qué pasa (Graciela).

A mí me hubiera gustado ingresar a la preparatoria y estudiar otra carrera, pero siempre fui una niña obediente y además sabía que económicamente mis papás no podrían solventarme esa carrera por el hecho de que ellos ya eran grandes y necesitaban que yo sacara adelante una carrera [...] me hubiera gustado ingresar a la prepa y estudiar en Ciencias Químicas [...] pero eso fue hace muchos años (Maru).

\section{Dimensión del tiempo educativo}




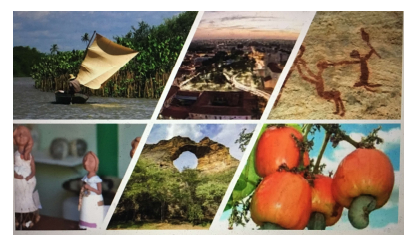

ISBN: 2675-1496 DOI: https://doi.org/10.26694/caedu.v1i2.9181

\section{Experiencias escolares}

La educación de Graciela estuvo marcada por profesores quienes utilizaban métodos tradicionales muy estrictos en los cuales segregaban a los alumnos, mientras que la educación de María Eugenia se caracterizó por su estancia en escuelas exclusivas para mujeres las cuales perpetuaban ideas sobre lo que un niño es y lo que una niña debía ser. En ambos relatos, las experiencias escolares configuraron la manera de percibir sus prácticas educativas en su ejercicio profesional:

[...] es por eso que a veces yo casi no castigo, o sea les grito a los niños, pero ya después los abrazo, después recuerdo... no quiero que pasen lo que yo pasé... es un trauma, entonces ahora sí ya recibo a los niños con gusto, ya les doy un abrazo, hasta les doy aplauso que cuando llegan peinados y limpios [...] entonces por eso trato de hacer mejor las cosas, para que los niños estén alegres y estén contentos en el salón (Graciela).

Reconozco que siempre cuidé que mis alumnos jugaran con juguetes propios de su sexo. [...] en mi salón siempre había carros y cubos para armar, pero era implícito que las niñas jugaran con cierto tipo de juguetes y los niños con otros (María Eugenia).

En el caso de la educadora Graciela, la unión y el apoyo fueron valores fundamentales que consideró importantes de transmitir a sus alumnos. Por su parte, la educadora María Eugenia se enfrentó a los cambios y al contexto social de la época actual, adaptarse a ella le significó una reestructuración de sus ideas, así como la reconfiguración de la percepción que tenía de sí misma.

\section{Formación docente inicial}

La formación docente de ambas educadoras estuvo marcada por los discursos reiterativos de los profesores sobre "el ser docente rural” que formó en ellas un imaginario acerca de lo esperado para su ejercicio profesional; mientras que para la educadora Graciela esta experiencia representó la motivación para dedicarse a su profesión al identificarse con las 


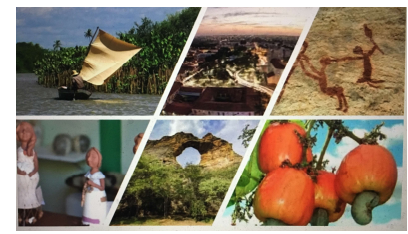

ISBN: 2675-1496 DOI: https://doi.org/10.26694/caedu.v1i2.9181

necesidades educativas del campo, para la maestra María Eugenia significó un desafío adaptarse a las limitaciones que conllevaba vivir en una comunidad rural.

Por otra parte, las materias relacionadas a la práctica profesional representaron angustia e incertidumbre para María Eugenia, ya que a pesar de tener el conocimiento no se sentía preparada para estar frente a grupo. Además de ello, elaborar los materiales para las prácticas le resultaba complicado, pues ella misma señala que no contaba con las habilidades necesarias para elaborar manualidades, no obstante, los materiales representaban la mayor parte de su calificación debido al imaginario que aún predominaba de las maestras desde la primera mitad del siglo XIX.

\section{Ejercicio profesional}

En el caso de ambas educadoras, el ejercicio de su profesión tuvo un inicio formal en comunidades rurales el cual representó para ellas una experiencia significativa enfrentarse a las necesidades educativas de dicho ámbito.

Graciela ha recorrido durante su trayectoria como educadora once jardines rurales y cinco urbanos, por su parte, María Eugenia laboró durante ocho años de sus 32 años de servicio en comunidades. Esta situación las ha llevado a construir una perspectiva diferente de ambos ámbitos, mientras que para Graciela el ámbito rural representó una mejor experiencia en cuanto a la relación con padres de familia, compañeros y directivos, para María Eugenia trabajar en dicho ámbito le mostró un panorama distinto frente a los jardines urbanos pues estos estaban marcados por la desigualdad y las precariedades en cuanto a estructura física y falta de materiales.

Por su parte, la educadora María Eugenia ejerció una parte de su profesión en un jardín de niños vespertino en la ciudad, esta vivencia le significó cambiar su dinámica cotidiana y enfrentarse a las condiciones ambientales del lugar, así como a la organización escolar. Tiempo después, demostró interés por seguirse preparando y fue así que en el año 2006 ingresó a la maestría de educación preescolar en la escuela normal del estado, la cual ella describe no le fue nada fácil, sin embargo, le ayudó a reconfigurar su propia 


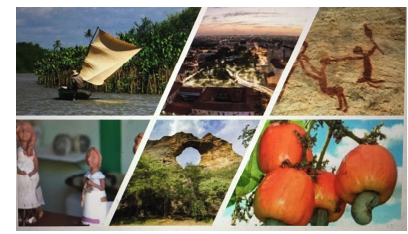

ISBN: 2675-1496 DOI: https://doi.org/10.26694/caedu.v1i2.9181

práctica. Esta experiencia le proporcionó años más tarde la posibilidad de convertirse en directora tras concursar y completar los requerimientos del programa de escalafón.

\section{Contacto con el magisterio}

Ambas educadoras pertenecen al Sindicato Nacional de Trabajadores de la Educación (SNTE) sección 56; vivieron su primera experiencia dentro del magisterio de manera similar puesto que acudían diariamente al sindicato con la esperanza de encontrar algún lugar de trabajo. La dificultad para conseguir una plaza docente dentro del sistema educativo radica en la ley de la oferta y la demanda de maestros que, año tras año, egresan con la idea de conseguir una plaza propia. No obstante, muchas de las veces, el tiempo de espera para acceder a una de estas plazas depende de la relación y la influencia que se tiene dentro del sindicato.

Al respecto, Graciela señaló que, aunque llevó tiempo, fue gracias a un conocido de su hermana que pudo obtener una plaza. En cambio, cuando María Eugenia egresó de la carrera, logró una plaza docente sin necesidad de tener alguna influencia, debido a la gran demanda laboral que implicó la política de cobertura en el nivel de preescolar. Por otra parte, siguiendo el relato de la educadora María Eugenia, es posible observar que la cultura magisterial promueve estereotipos de género en el nivel preescolar más que en otros niveles educativos al estar conformado casi en su totalidad por mujeres. Existe un rol tradicional y de representación simbólica como: organización, creatividad, afecto y entrega. Al mismo tiempo, se advirtió la presencia de mujeres en puestos administrativos, a diferencia de los varones quienes ocupan cargos como líderes sindicales.

Una vez dentro del sistema educativo, ambas educadoras obtuvieron su plaza en comunidades alejadas a la capital, por lo tanto, tenían que solicitar sus cambios de adscripción ante el sindicato para poder ir acercándose poco a poco a la ciudad. No obstante, este es otro proceso que toma tiempo y que varía según las necesidades educativas de la época en la que se encuentra el contexto educativo. Mientras que Graciela describe que vivió este proceso sin problema, María Eugenia señaló en su relato que hubo un estancamiento en el cual las maestras rurales no podían solicitar su cambio a la ciudad 


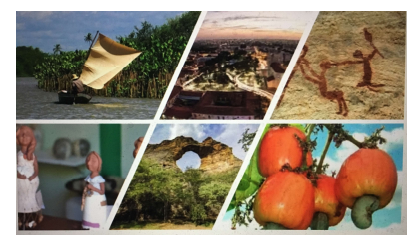

ISBN: 2675-1496 DOI: https://doi.org/10.26694/caedu.v1i2.9181

pues las maestras urbanas no podían dejar sus plazas debido a que no contaban con la antigüedad requerida para poder jubilarse.

En este sentido, la ley del Instituto de Seguridad y Servicios Sociales de los Trabajadores del Estado (ISSSTE) cambió en el año 2006 bajo el régimen transitorio y por cuentas individuales, la cual establece quiénes tienen derecho a pensionarse, así como la modalidad para el retiro que incluye años de servicio y edad. De esta forma, ambas educadoras se vieron perjudicadas ya que aumentó el tiempo que les restaba para jubilarse.

Otro aspecto que es importante considerar en el análisis es la profesionalización docente, la cual se refiere a las reformas que tienen como objetivo mejorar los estándares de calidad de la Secretaría de Educación Pública (SEP). Dicha profesionalización, acreditó que ser profesora de educación preescolar como licenciatura en el año de 1984.

A diferencia de Gabriela, María Eugenia egresó de la profesión de educación preescolar cuando aún no era reconocida como licenciatura, por lo tanto, años más tarde, ingresó a la licenciatura de educación preescolar en la Universidad Pedagógica Nacional, la cual ofertó la licenciatura por disposición oficial. Acreditar la licenciatura, así como otros niveles de posgrado posibilitaba a las educadoras a aspirar a cargos directivos, en el caso de la educadora María Eugenia haber cursado la maestría y reunir el puntaje máximo en el examen de carrera magisterial le brindó la posibilidad de asumir un puesto como directora.

El programa de carrera magisterial, según la Secretaría de Educación Pública tuvo vigencia a partir del año de 1993 y concluyó en el 2013, cuando fue sustituido por la Ley General de Servicio Profesional Docente. Este programa es un sistema gradual y escalonado de estímulos salariales para los profesores de Educación Básica (preescolar, primaria, secundaria y grupos afines), el cual tenía como propósito coadyuvar a elevar la calidad de la educación mediante el reconocimiento y apoyo a los docentes, así como el mejoramiento de sus condiciones de vida, laborales y educativas. 


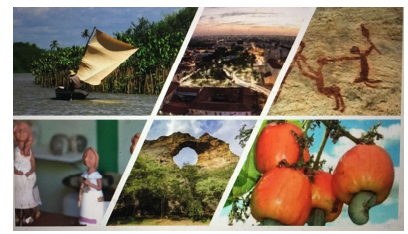

ISBN: 2675-1496 DOI: https://doi.org/10.26694/caedu.v1i2.9181

Sin embargo, ascender los niveles de carrera magisterial era un proceso igual de complicado que el otorgamiento de plazas ya que implicaba una serie de requisitos que burocratizaban más el servicio y en ocasiones se prestaba a un mal manejo del programa, por ejemplo, la corrupción. Al respecto, la educadora Graciela señala: "nunca entré porque se manejaban puras injusticias y tenías que pagar. [...] aunque no es en todos lados, unos entran porque verdaderamente lo lograron y otros entran porque pagaban". A diferencia de Graciela, María Eugenia vivió una experiencia diferente ya que ingresó al último nivel de carrera magisterial e incluso sacó el mejor puntaje del programa, esta vivencia la llevó representar a las educadoras del estado y a recibir un reconocimiento, así como un estímulo económico de la mano del presidente de la república, de aquel entonces, Felipe Calderón.

De ahí que las políticas de profesionalización y valoración social del magisterio representan un elemento identitario relativamente positivo en las educadoras, ya que configura la propia de manera de concebirse junto con las experiencias que han vivido durante su formación inicial, al mismo tiempo que atribuye las características de su identidad de género.

\section{Dimensión del tiempo social e histórico}

Roles y estereotipos de las educadoras

Desde el punto de vista social, ser educadora implica una serie de imaginarios colectivos en las que el género es una categoría de análisis fundamental en la construcción de su identidad, puesto que, como lo menciona López (2006) la condición de ser mujer maestra conlleva una serie de estereotipos y ciertos sistemas de creencias que denominan el "deber ser" de su función como docentes.

En este sentido, Graciela reconoció que anteriormente las educadoras representaban una imagen que respondía al estereotipo de la maestra "bonita e impecable". Al mismo tiempo, señaló que esas características les otorgaba un estatus privilegiado dentro de su mismo gremio ya que constantemente hacían una comparación entre ellas y las maestras de educación primaria. Al respecto señala: 


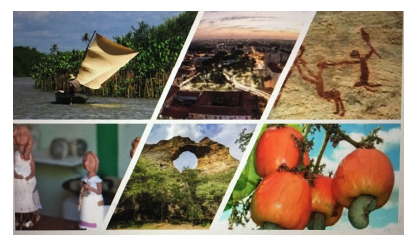

ISBN: 2675-1496 DOI: https://doi.org/10.26694/caedu.v1i2.9181

[...] siempre en alguna reunión o en algo las educadoras estábamos un poquito más arriba por la presentación y el trabajo [...] decían los demás: "las de primaria son unas fodongas, son unas gordotas que no se visten bien, van, así como se levantan", y las educadoras éramos como que un poquito más detallistas en todo eso".

Por su parte, la educadora María Eugenia admitió que en la Secretaría de Educación Pública todavía son consideradas como las maestras "sumisas" que cumplen y presentan bien su trabajo. Como ella lo menciona: “[...] en la misma secretaría así nos ven o sea saben que cumplimos con todo y que hacemos todo, pero dicen: “ $\mathrm{A}$ y, las de preescolar!", siempre nos han catalogado así.

Asimismo, señaló que en su profesión existen muchos estereotipos por el hecho de ser mujeres y trabajar con niños chiquitos, los cuales corresponden al imaginario cultural e histórico que se tenía de las mujeres sobre su papel en la educación como una extensión de su rol materno.

Con relación a esto, tanto María Eugenia como Graciela coincidieron con educadores hombres durante su trayectoria formativa y laboral; ambas señalaron que no les fue fácil ser aceptados, además de que continuamente eran cuestionados por su preferencia sexual. Esta situación tiene que ver con que culturalmente la profesión de las educadoras ha sido pensada exclusivamente para mujeres, por lo que no es común encontrarse con hombres que se dediquen a la educación preescolar.

\section{Función social del jardín de niños}

Ambas educadoras perciben que socialmente el jardín de niños ha sido considerado como una instancia en donde los padres pueden llevar a sus hijos para ser cuidados y entretenidos. Ambas coinciden en que la educación preescolar no ha sido tomada en cuenta como una profesión con agencia puesto que no tiene el mismo reconocimiento que otros niveles educativos. 


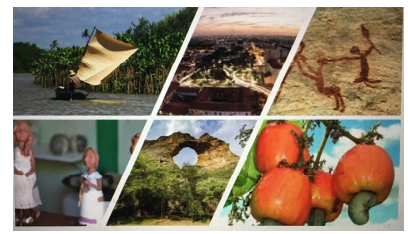

ISBN: 2675-1496 DOI: https://doi.org/10.26694/caedu.v1i2.9181

Por su parte, la educadora Graciela señaló en su relato que incluso dentro de su propia familia su profesión ha sido desacreditada por el hecho de trabajar con niños chiquitos. Al respecto señala:

En mi familia hay tres hermanos que [dicen]: “¡ay es bien fácil como maestra!", pero a veces llego y les platico: “es que tengo que hacer esto, es que no puedo ir por esto, es que estoy planeando, es que estoy haciendo actividades", y me dicen: "eso te lo avientas en un ratito; nada más los pones a jugar”, o sea, se les hace muy fácil.

Sin embargo, de acuerdo a su propia experiencia advirtió que la percepción que se tiene hacia el jardín de niños como hacia las educadoras cambia según el ámbito y el contexto social. Mientras que en el ámbito urbano la educación preescolar tiene menor relevancia, en el ámbito rural las educadoras tienen mayor reconocimiento. Como ella lo menciona:

Allá en la comunidad se reúnen todos los papás a la hora de la salida y a la hora de la entrada, allá hasta ellos se comunican y aquí como que somos más independientes, o sea agarro a mi niño y [preguntan]: “¿no hay tarea maestra?”, y vámonos. Aquí, por ejemplo, no está lo de nosotras como educadoras festejarle a la mamá, ni la mamá nos festeja a nosotros. En las comunidades [dicen]: “¡Ay, es día de la educadora! o ¡Es día del maestro! ¡Vamos a llevarle, aunque sea un taquito!”, pero ahí están ¿sí? es más bonito en una comunidad que la ciudad.

Por su parte, la educadora María Eugenia reconoció en su relato que con el paso del tiempo la percepción hacia el jardín de niños ha ido cambiando ya que anteriormente tenía menos reconocimiento. Como ella lo menciona:

Después de 32 años de servicio creo que ahora sí ha cobrado más relevancia el preescolar pero cuando yo ingresé a trabajar todavía había papás que se negaban a mandar a los niños al preescolar y 


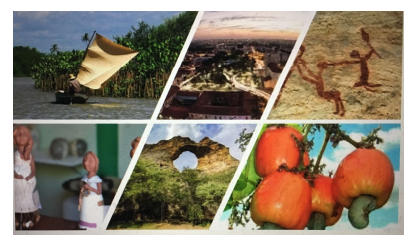

ISBN: 2675-1496 DOI: https://doi.org/10.26694/caedu.v1i2.9181

decían que mejor los iban a echar directo a la primaria, pero sí creo que en esa parte ha cambiado.

En este sentido, el descrédito que ha tenido la educación preescolar tiene su origen en los antecedentes históricos de las mujeres en la educación ya que la condición de género influye en el reconocimiento de su profesión dentro de un sistema educativo androcéntrico.

\section{Imaginario de la educadora ideal}

Para Graciela una buena educadora es amorosa y comprensiva, asimismo, es aquella que prepara festivales, decora su salón y elabora manualidades, ya que considera que dichas características favorecen al aprendizaje de sus alumnos, sin embargo, señaló que la SEP les ha quitado valor a las actividades recreativas:

[...] como que se me está quitando el espíritu de educadora, porque ya no adornamos el salón y ya no hacemos material; ya no hacemos nada porque como que hay un tope de la secretaría, pura papelería y aprendizaje, y ya no le damos importancia a otras cosas.[...]

En cambio, para María Eugenia la educadora ideal es aquella que mantiene relaciones asertivas con sus compañeras de trabajo, asimismo, es quien cuida de su imagen y se mantiene joven y en buen estado físico para desempeñar una buena función docente. Por otra parte, considera que una buena directora es organizada, responsable, diplomática y líder:

Yo siempre que he dicho que un buen directivo es aquél que no le lleva problemas a la supervisora [...] el directivo se tiene que ganar el respeto de los padres de familia [...] o sea es mucha diplomacia $[\ldots]$ quien tiene que poner el ejemplo es el directivo.

En ambos relatos se puede observar que el imaginario ideal de las educadoras corresponde las experiencias personales y a sus trayectorias formativas, asimismo, responde a los estereotipos que interiorizaron en su formación como docentes, 


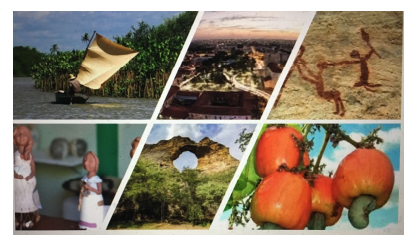

ISBN: 2675-1496 DOI: https://doi.org/10.26694/caedu.v1i2.9181

supeditadas a la obediencia y a un buen comportamiento, es decir, a mantener y reproducir el status quo.

\section{Doble jornada de las educadoras}

Como sujetos histórico-sociales, las mujeres fueron relegadas del ámbito laboral y profesional debido a la jerarquización de los sexos y a los mandatos de género. Fue hasta la segunda mitad del siglo XIX cuando las mujeres fueron reconocidas como sujetos libres e independientes capaces de incursionar en dichos ámbitos, no obstante, los espacios laborales a los que accedieron perpetuaban el imaginario cultural y colectivo de su identidad de género que perpetúan las condiciones de subordinación y marginalidad en las que se encuentran.

Por otro lado, en el caso de las maestras, su trabajo representaba una extensión de sus labores domésticas y sus cualidades maternas por lo que, socialmente, fue una carrera bien vista y mejor aceptada a diferencia de otras profesiones. Una vez que las mujeres accedieron al ámbito laboral no debían descuidar sus labores domésticas, por lo tanto, ejercían una doble jornada laboral.

En el caso de la educadora Graciela, la doble jornada consiste en la crianza de sus hijos y en atender las labores domésticas de su hogar, ya que como señala en su relato, no contaba con alguien que le ayudara con las tareas de la casa. Con relación a su condición de madre y educadora, comentó que sus embarazos no interfirieron en sus clases, sin embargo, señaló que una vez que se convirtió en madre tenía que resolver el conflicto de quién cuidaría de sus hijos. A diferencia de Graciela, María Eugenia era una educadora soltera y sin hijos, no obstante, la doble jornada consistía en el cuidado de sus padres y en su labor como ama de casa, incluso en su relato deja ver como el cuidado de sus padres interfería con sus proyectos y metas de estudio.

\section{Reflexiones finales}

Las experiencias personales y familiares, así como el contexto social y cultural de cada educadora determina su identidad docente. Ambas educadoras relacionaron su identidad docente con los imaginarios sociales que históricamente les ha posicionado en 


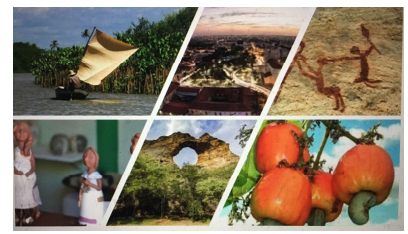

ISBN: 2675-1496 DOI: https://doi.org/10.26694/caedu.v1i2.9181

una relación de inferioridad y marginalidad con respecto a los hombres. Así mismo, los estereotipos de género que existían dentro de su situación familiar las llevó a cursar una licenciatura socialmente aceptada, suceso que les permitió lograr cierta autonomía e independencia económica. Las políticas de revalorización de la función social del docente contribuyeron de igual manera a gestar acciones que contribuyeron a una mayor equidad y justicia laboral. Es por ello que, ser educadora significó para ambas un privilegio, por el hecho de haber encontrado la estabilidad que sus familias auguraban para ellas:

Ser educadora es la profesión que me ha permitido vivir en el sentido de que me ha permitido tener casa, comida, seguridad social y grandes lujos porque para mí ha sido un gran lujo tener un carro, estrenar una casa, viajar. [...] me ha permitido ser reconocida socialmente por muchísima gente (María Eugenia).

Pues [para mí ha significado] una gran satisfacción el llegar hasta donde estoy porque yo no estaba para educadora, pero conforme iban pasando los días tenía que cumplir con un compromiso y me fue llamando la atención [...] y fue más el gusto por los niños (Graciela).

Las trayectorias profesionales dan cuenta de una lucha constante por sobresalir en un mundo laboral en el que los hombres tienen un papel protagónico en puestos que implican la toma de decisiones, por demostrar sus capacidades y talentos, así como por contrarrestar el demérito social de su profesión: ambas señalan su agencia y su convencimiento por demostrar que la educación preescolar va más allá del cuidado de los niños, es decir, la educación formal de los mismos y la trascendencia que exige una adecuada preparación al intervenir en una etapa vital del desarrollo humano, así como de gran trascendencia social y económica.

La reconstrucción de la identidad de las educadoras exige visibilizar y cuestionar el entramado social desde el cual se sostiene el lugar de subalternidad que ocupan las mujeres como profesionales de la educación. En ese sentido, se hace indispensable 


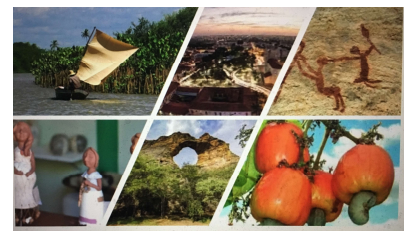

ISBN: 2675-1496 DOI: https://doi.org/10.26694/caedu.v1i2.9181

conformar, desde las instituciones, espacios de formación reflexiva y crítica que permita promover procesos de deconstrucción del imaginario social que reproduce estereotipos. De igual forma, es imprescindible fortalecer políticas que contribuyan a recuperar la dignificación de la profesión y generar relaciones de mayor equidad y justicia social.

\section{Bibliografía}

- BOLÍVAR, Antonio. Investigar la identidad profesional del profesorado: una triangulación secuencial. Forum, Qualitative Social Research, Vol.6 No. 1 Art. 12,2005 .

- BRUNER, Jerome. La fábrica de historias: derecho, litratura, vida. Buenos Aires: Fondo de Cultura Económica de Argentina, S.A, 2003.

- CACHO, Manuel. Profesores, trayectoria e identidades. Revista Latinoamericana de Estudios Educativos, vol. XXXIV, núm. 3, México, 2004.

- DUBAR, Claude. La crisis de las identidades. La interpretación de una mutación. Barcelona.: Bellaterra, 2002.

- DUCOING, Patricia. Sujetos, actores y procesos de formación, tomo II. México: COMIE, 2005.

- ESCALANTE, María Guadalupe. La escuela normal de profesoras durante la revolución mexicana: posibilidades de educación para la mujer. In: Hernández, Francisco, (Org.). Desafíos en la formación del profesorado en el siglo XXI: reflexiones en torno a la educación normalista en México. San Luis Potosí: Editorial Pedro Vallejo, 2013, p. 13-52.

- FILLOUX, Jean Claude. Intersubjetividad y formación. Buenos Aires: Ediciones Noveduc, 2004.

- GALVÁN, Luz Elena; LÓPEZ, Oresta. Entre imaginarios y utopías: Historias de maestras. México: La Casa Chata, 2008.

- GARCÍA, María Guadalupe. Las maestras tapatías: celibato y disciplina, 18671910. In: Galván, Luz Elena; López, Oresta. Entre imaginarios y utopías: Historias de maestras. México: La casa Chata, 2008, p. 127-152 


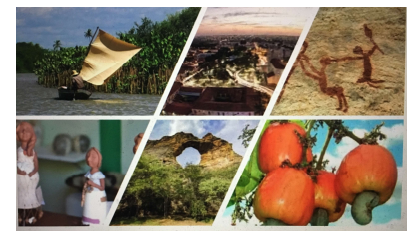

ISBN: 2675-1496 DOI: https://doi.org/10.26694/caedu.v1i2.9181

- GOODSON, Ivor. Historias de vida del profesorado. Madrid: OCTAEDRO, 2004

- GUERRERO, Patricio. La cultura. Estrategias conceptuales para entender la identidad, la diversidad, la alteridad y la diferencia. Ecuador: Abya-Yala, 2002.

- LÓPEZ, Oresta. Las maestras en la historia de la educación en México: contribuciones para hacerlas visibles. Revista Electrónica Sinéctica, México, 28, p. 4-16, 2006.

- LÓPEZ, Oresta. Porfirianas y revolucionarias: dos estudios de caso de maestras mexicanas. In: Galván, Luz Elena; López, Oresta. Entre imaginarios y utopías: Historias de maestras. México: La casa Chata, 2008, p. 275-306.

- NIAS, Jennifer. Primary teachers talking: A study of teaching as work. London: Routledge, 1989.

- PUJADAS, Joan. El método biográfico: El uso de las historias de vida en ciencias sociales. Madrid: Centro de Investigaciones Sociológicas, 1992.

- SCOTT, Joan. La mujer trabajadora en el siglo XIX. In: Duby, George; Perrot, Michel (coord.) Historia de las mujeres en occidente, vol. IV,. Madrid:Taurus, p. 427-480, 2001

- STREET, Susan. Ser maestra: historia, identidad y género. Revista Electrónica Sinéctica, México, 28, p. 4-16, 2006.

\section{Fuentes orales y autobiográficas}

- Entrevistas con la educadora María Eugenia Tobías Tobías, realizadas por autor, Fátima Hernández. San Luis Potosí, S.L.P, 1 de marzo, 8 de marzo y 9 de marzo de 2017.

- Entrevistas con la educadora Graciela Velázquez Almendarez, realizadas por autor. San Luis Potosí, S.L.P., 7 de marzo, 9 de marzo, 14 y 16 de marzo de 2017.

Manuscrito autobiográfico de la educadora María Eugenia Tobías Tobías. Proyecto de titulación de la licenciatura en Educación Preescolar: UPN, 19 